\title{
FDI and Economic Development: Evidence from Mainland China
}

\author{
Liyan Liu ${ }^{1,2}$ \\ ${ }^{1}$ Department of Economics Phylosophy, Dongbei University of Finance and Economics, Dalian, China; ${ }^{2}$ Economics and Manage- \\ ment Department, Beijing Institute of Petrochemical Technology, Beijing, China. \\ E-mail: lucyliuliyan@bipt.edu.cn
}

Received June 28 ${ }^{\text {th }}$, 2011; revised September $9^{\text {th }}, 2011$; accepted September $26^{\text {th }}, 2011$.

\begin{abstract}
Endeavors have been made in this paper to discern the long-run relations between FDI (Foreign Direct Investment) and economic development in China in the comprehensive framework, which incorporates determinants as output, FDI, capital formation, employment, human capital and international openness. VAR (vector autoregressive models) Impulse Response, Variance Decomposition, Johansen Co-integration and VECM (vector error correction) have been estimated, focusing on the long-run structural relations; findings indicate that in the long run, FDI tends to decrease economic growth; economic development in China seems to be fueled by domestic capital accumulation and employment growth; FDI inflows do crowd out domestic capitals, and reduce employment growth.
\end{abstract}

Keywords: FDI, Economic Development in China, VAR, Co-Integration

\section{Introduction}

FDI (Foreign Direct Investment) and economic development in host country has always been an enduring interest in the development literature, particularly in the context of China which have experienced unprecedented economic growth and enjoyed exceptional FDI inflow. Since the reform and opening up policy initiated in 1978, China achieved an impressive economic growth, with output growing in excess of 7\% each year; since 1992 China has become the largest FDI recipient in the developing world and globally the second (next to the US). China has attracted $\$ 622$ billion US dollars of FDI for the period 1980 to 2005 (UNCTAD (2006)). In 2004, FDI inflows constituted $7 \%$ of gross capital formation; $21 \%$ of China's tax revenue were from foreign-invested enterprises (FIEs), 28\% of industrial output and 57\% of exports was produced and created by FIEs (China Statistical Year Book(2005)).

Success both in economic development and attracting FDI in China has generated several studies on the role of FDI in economic development; however, the research has failed to generate a consensus on the relations between aggregate output, FDI, and other possible ancillary growthmotivating determinants, as capital formation, employment, human capital, etc. For example, Kevin H. Zhang [1] established a growth model, and applied panel data estimation and found that FDI seemed to promote income growth, and that this positive growth-effect seemed to rise over time and to be stronger in the coastal than the inland areas. Shan [2] developed a VAR model but used technique of innovation accounting to generate the relationship between FDI with output via labor, investment, international trade and energy consumed, and concluded that FDI was not a significant motivator for growth, but an important determinant; Liu et al [3] focused on relations between FDI and GDP via international trade; Tan et al [4] found that impact of FDI on GDP is small but significant. One of the reasons for these conflicting conclusions of these studies is that they focus on one or several different aspects or channels through which FDI might impact an economy's development. In this paper, efforts are exerted to establish a more comprehensive framework, in which potential determinants would be incorporated, to identify long-run relations between FDI and output in a general equilibrium framework, and relations with other determinants as domestic capital and employment.

The rest of this paper is organized as follow: Section 2 contains the definition and measurement of variables, including their order of integration. Begin with a introduction of VAR methodology, Section 3 contains the VAR estimates, diagnostic statistics, impulse response and variance decomposition; Section 4 is the core section, fo- 
cusing on the Johansen co-integration test, identified cointegrating vectors and VECM; Section 5 is the concludeing section, which presents the conclusions on the role of FDI amongst other variables upon output, and other determinants as domestic capital, employment.

\section{Data Description}

\subsection{Definition and Measurement}

Output (GDP): Real Gross Domestic Product is used to capture the total output of economic activities, for, in some extent, GDP represents the size of the potential market in the host country, which is an important determinant for MNCs (multi-national companies) when considering the location of their FDI.

Capital Formation (CF): Capital formation is measured by annual domestic capital formation as a percentage of annual GDP. Capital formation is a significant factor for economic growth, and its ratio to GDP indicates the degree of an economy's industrialization and development.

Employment (EM): annual average employment is used to measure labor force participation in economic activeties. Employment is measured by annual total number of persons employed at year-end.

Openness (OPEN): openness refers to international openness of an economy, and here it is defined as the ratio of sum of annual imports and exports to annual GDP. As one of the three major impetus of China's economic growth, International trade promote employment, competition, innovation and, thereby, economic growth. Moreover, international openness is frequently cited as a critical factor for attracting FDI.

Human capital (HK): Human capital is defined by school enrollment ratio, which is the usual case in study. Human capital is estimated as the ratio of student enrollment in high education to the newly added population of the year. The latter is calculated as the product of total population and the birth rate of the relative year. The enhancement of a nation's human capital will lead to economic growth by means of the development of new forms of technology and efficient and effective means of production.

FDI (FDI): FDI is measured as the value of annual FDI inflow. The utilized annual value of FDI inflow refers to the investment that actually occurred in China each year, which should be more precise than contracted value in determining its impact on GDP; for it takes time for capital transferring and equipment shipping, which results in a gap between the contracted FDI and the actually utilized FDI.

Generally if the data of HK, FDI and OPENNESS is over a long historic span and by detailed types of academic training, age cohorts, real utilized investments and types of trade, a more detailed assessment of the role of
FDI and its impacts on output under this comprehensive framework of inter-relations with human capital, Openness, CF and EM could be attempted. The conventional data used here, together with the short time span for which these are available, suggest that the information that we uncover will tend to relate to the long run consequences of changes in those data. Hence the potential value of the co-integrating vectors we explore.

\subsection{Data on the Six Time Series}

The annual data for GDP and Employment are collected from China Statistics Year Book; annual data for Capital Formation, FDI, Openness and HK are collected and calculated from China Statistics Year Book (for the time span 1985-2008); data for the time span 1978-1984 are collected from China Compendium of Statistics, China Population \& Employment Statistics Year Book and China Labor Statistical Year Book. The time series cover the period 1978 to 2008. GDP are measured in real RMB at 1990 prices to eliminate the influence of price changes, and FDI inflows are converted into real RMB 1990 price by the annual average series of RMB to US dollar exchange rate. Openness is measured as the ratio of total import and export value to GDP value of the relative year; likewise, capital formation is defined as the ratio of capital formation flowing to GDP value of the relative year. All variables are converted into logarithms in the estimation as shown in Figure 1.
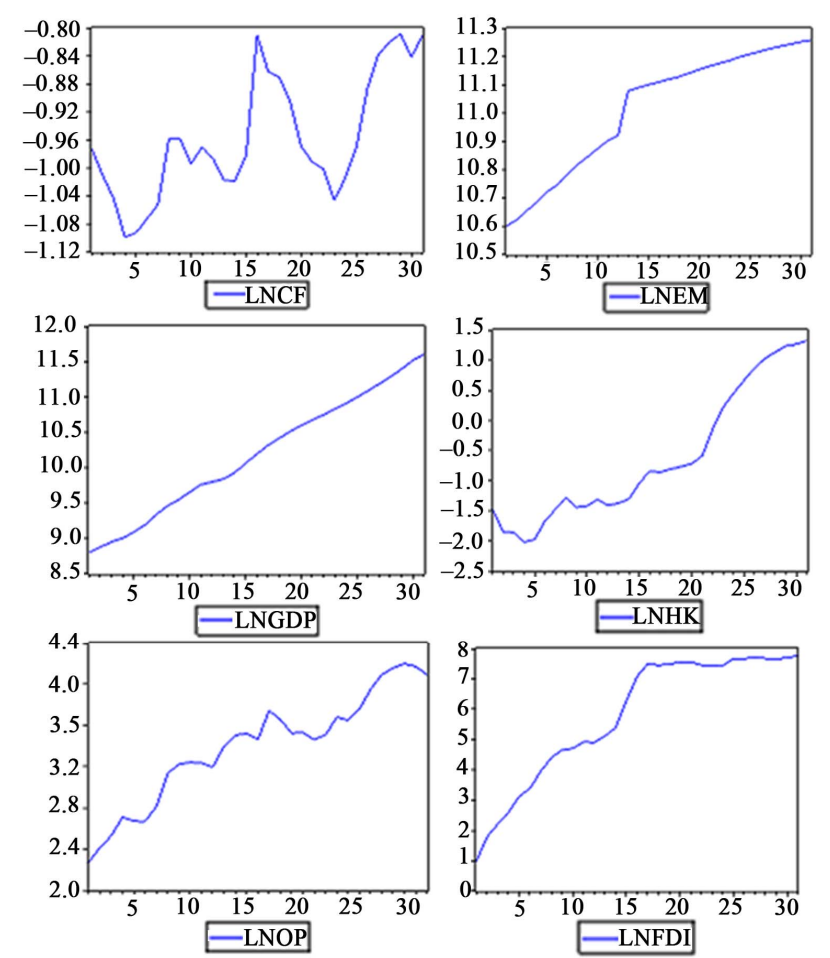

Figure 1. Six variables in logarithmic values. 
For the purpose of estimation it is necessary to examine the order of the variables. On the basis of Augmented Dickey-Fuller [5,6] (ADF) test and Phillips-Perron [7] (PP) test all the six variables are I (1) series, as shown in Table 1.

For FDI, the test neither includes an intercept nor a trend term; for CF, EMP, HK, and OPEN, the tests include an intercept and a statistically insignificant trend term; therefore, trend terms are excluded and estimates are performed with the statistically significant intercept term. For GDP, both trend terms and intercept are included. It follows, therefore, that we can investigate the presence of long-run, co-integrating relations, between the variables, especially other variables' impact on GDP (in its logarithm value).

\section{VAR Methodology, Estimates and Diagnostic Statistics}

\subsection{Background}

Since the critique of Sims [8] in the early eighties of the last century, multivariate data analysis in the context of vector autoregressive models (VAR) has evolved as a standard instrument in econometrics ${ }^{1}$. Structural vector autoregressive models (SVAR) allow the explicit modeling of contemporaneous interdependence between the left-hand side variables, which seems to bypass the shortcomings of VAR models. With the emergence of concept of co-integration developed by Engle and Granger [9] for modeling and testing economic relationships, these branches of research are developed in the form of vector error correction (VECM) and structural vector error correction models (SVEC) ${ }^{2}$.

Table 1. Unit root test.

\begin{tabular}{cccc}
\hline Variables & ADF & PP & Conclusion \\
\hline$\Delta \operatorname{lnGDP}$ & $-4.112098^{* * *}$ & $-2.985861^{* *}$ & stationary \\
$\Delta \operatorname{lnCF}$ & $-4.215340^{* * *}$ & $-4.226392^{* * *}$ & stationary \\
$\Delta \operatorname{lnEM}$ & $-4.903664^{* * *}$ & $-4.919629^{* * *}$ & stationary \\
$\Delta \operatorname{lnOP}$ & $-4.574890^{* * *}$ & $-4.488097^{* * *}$ & stationary \\
$\Delta \operatorname{lnFDI}$ & $-2.617893^{* *}$ & $-2.586712^{* *}$ & stationary \\
$\Delta \ln \mathrm{HK}$ & $-4.215340^{* * *}$ & $-3.989702^{* *}$ & stationary \\
\hline
\end{tabular}

***1\% level, **5\% level, *10\% level MacKinnon (1996) one-sided pvalues; LnGDP, lnECF, lnEMP, lnOP, lnFDI, lnHKH refer to the logarithm values of GDP, capital formation, employment, openness, FDI, human capital of common high education.

${ }^{1}$ This vignette has been publicized as an article in the Journal of Statistical Software (see Pfaff 2008).

${ }^{2}$ Lutkepohl (2006), Hendry (1995), Johansen (1995), Hamilton (1994), Banerjee, Dolado, Galbraith, and Hendry (1993).
A structural VAR can be written as a simple extension of the by now popular semi-structural form, adopted by Bernanke and Blinder [10]. Thus:

$$
\begin{aligned}
S y_{t} & =B x_{t}+A(L) y_{t}+\varepsilon_{t}: E\left(\varepsilon_{t}\right)=0 ; \\
y_{t} & =n \times 1 ; x_{t}=k \times 1
\end{aligned}
$$

$A(L)$ is a matrix polynomial in the lag operator $L$ for $\mathrm{a} \operatorname{VAR}(p)^{3}$ :

$$
A(L)=A_{1} L+A_{2} L^{2}+\ldots+A_{p} L^{p}
$$

$S, A$ and $B$ are conformable matrices. Any structural contemporaneous parameters on the endogenous variables are, contained in the matrix $S$. six endogenous variables are contained in the vector $y_{t}$ here and the $k$ elements in that vector are: deterministic terms, intercepts and a time trend, may be included in the estimation that follows.

The MA representation of Equation (1) is:

$$
y_{t}=\Theta(L) \varepsilon_{t}: \Theta=[S-A(L)]^{-1}
$$

Here: $E\left[\varepsilon_{t}\right]=0$ and, as in Sims, $E\left[\varepsilon_{t} \varepsilon_{t}{ }^{\prime}\right]=I_{n}$.

Findings from the moving average representation (3) indicate that to make the responses of the system approach zero value over time, and mathematically stable, the roots of the matrix polynomial, $\left|I_{n}-(S)^{-1} A_{(L)}\right|=0$, must be outside the unit circle in absolute value, or equals to 1 in the presence of co-integration. If the VAR is written in companion form, the roots of the companion matrix should be less than one in absolute value or equal to 1 in the presence of co-integration [11].

\subsection{VAR Estimates and Diagnostic Statistics}

One of the significant factors for VAR is lag structure selecting, which should meet several criteria: (1) the system must be mathematically stable; (2) standard lag selection and lag length criteria (LR, FPE, AIC, SC, $\mathrm{HQ}^{4}$ ); (3) the residuals for the individual equations should be normally distributed with no AR and no Heteroskedasticity; and so for the vector (the system) of residuals from the VAR, under which conditions the distributional properties of trace test for the presence of co-integrating vec tors have been evaluated[12]. However, Johansen points out that the normality assumption per se might not be important, but that the presence of ARCH might be [13]; and Juselius holds that the absence of normality is of no

${ }^{3}$ Without loss of generality, deterministic regressors are suppressed in the following notation. Furthermore, vectors are assigned by small bold letters and matrices by capital letters. Scalars are written out as small letters, which are possibly sub-scripted.

${ }^{4} \mathrm{LR}$ : sequential modified LR test statistic (each test at 5\% level); FPE: Final prediction error; AIC: Akaike information criterion; SC: Schwarz information criterion; HQ: Hannan-Quinn information criterion. 
significance if it is due to excess kurtosis [14].

Following the standard lag length selection criteria as LR, FPE, AIC, SC, HQ, the lag structure test indicates that three lags is the best lag order for the VAR estimated, which also meet with the mathematically stable requirement. The system-wide statistics are shown in Table 2 (with full equation available on request, since it takes too much space). Given the six time series exhibit autocorrelation, therefore, it is not surprising that goodness-of-fit of the six variables are high, which is also the case for adjusted values.

Statistics for VAR Residual Serial Co-relation LM test $\left(\mathrm{H}_{0}\right.$ : no serial correlation at lag order $\left.\mathrm{h}\right)$ exclude serial corelation, as the statistics for the test goes as:

$\operatorname{LM}(1)=42.79264$, P-value $=0.2025$;

$\operatorname{LM}(2)=31.19828$, P-value $=0.6962$;

$\mathrm{LM}(3)=36.96586, \mathrm{P}$-value $=0.4241$.

Moreover, VAR Residual Heteroskedasticity Tests (no cross terms, since observations are insufficient for cross terms) indicate that there is no heteroskedasticity in the residuals (joint test Chi-sq $=533.2083, \mathrm{P}=0.1778$; and value for Chi-sq. of all the individual components are ranging from 17.44536 to 28.77235 , P-value from 0.2480 to 0.8291 ). Therefore, the residuals possess attributes that are acceptable for evaluation of presence of co-integrating vectors in the system.

\subsection{VAR Impulse Response}

As the beginning of VAR estimate for the role of variables in influencing FDI and GDP, impulse response of these variables is to be examined, focusing on response of other variables to FDI and response of GDP to other variables in the short run. In doing so, Cholesky decomposition and generalized decomposition both of periodby-period and accumulated are applied (with full estimates available on request). As in almost universal findings in the literature, responses possess high standard error, shown by dotted lines.

Therefore, in short run, conclusions can be extracted as: 1) GDP is generally promoted by the increasing of capital formation, employment, openness of the economy, with comparatively substantial enhancement by the increase of employment, both period-by-period and accumulatively; however, GDP responses considerably slightly and even a bit of negatively to the increase of FDI, both period-by period and accumulatively; (2 in period-byperiod study, FDI itself reduced by the increase of other five variables; FDI response positively to the increase of capital formation and employment; first positively and after reaching time period 3 then negatively to the increase of GDP; generally fluctuating to the increase of openness and human capital; 3) in the accumulative study, FDI reacts actively to the increase of FDI itself, openness, capital formation and employment, with the latter two possessing a larger extent of enhancement; reacts generally negatively to the increase of GDP and human capital.

\subsection{VAR Variance Decomposition}

The variance decompositions from the Cholescky decomposition following the order shown in the first row of the tables are described by Table $\mathbf{3}$ and Table $\mathbf{4}$ for GDP and FDI respectively, based on 1000 Monte Carlo replication.

As shown in Table 3, the standard errors indicate that GDP is largely and statistically influenced by its own fluctuations, though its influence seems to be tailing off over the time period; the other variable contributes to GDP is EM and HK, with an increasing trend over time period; FDI only plays a numerically small role in the fluctuations of GDP.

Likewise, FDI contributes considerably to its own fluctuations, with a decreasing trend over time period; GDP and EM contributes significantly to the fluctuation of FDI, ranging from $17 \%$ to $38 \%$, $7 \%$ to $46 \%$ respectively; HK contributes from $10 \%$ to $38 \%$ over time period, reaching its bottom floor as $4.5 \%$ in the fifth time period; then comes CF, whose influence in FDI variance increasing steadily over the ten time period; the influence of OP is numerically limited, which goes to the last of the five other variables.

\section{Johansen Co-Integration and VECM Findings}

\subsection{Johansen Co-Integration}

Estimation statistics of VAR indicate us to investigate the presence of co-integration between the variables, which allow us endeavor to identify long-run relationships between GDP and FDI under more comprehensive frame work of six variables.

Table 2. VAR estimates overall statistics (rounded up).

\begin{tabular}{cllllll}
\hline$R^{2}$ & 0.999556 & 0.942877 & 0.989401 & 0.994107 & 0.980601 & 0.997709 \\
\hline Ajusted-R & 0.999223 & 0.900034 & 0.981452 & 0.989687 & 0.966052 & 0.995990 \\
S. E. eq. & 0.022481 & 0.028607 & 0.026676 & 0.111519 & 0.087417 & 0.115830 \\
F-stat. & 3000.169 & 22.00792 & 124.4673 & 224.9268 & 67.39912 & 580.5523 \\
\hline
\end{tabular}


Table 3. Variance decomposition of LNGDP.

\begin{tabular}{|c|c|c|c|c|c|c|c|}
\hline $\mathrm{P}$ & S. E. & LNGDP & LNCF & LNEM & LNHK & LNOP & LNFDI \\
\hline \multirow{2}{*}{1} & \multirow{2}{*}{0.022481} & 100.0000 & 0.000000 & 0.000000 & 0.000000 & 0.000000 & 0.000000 \\
\hline & & $(0.00000)$ & $(0.00000)$ & $(0.00000)$ & $(0.00000)$ & $(0.00000)$ & $(0.00000)$ \\
\hline \multirow{2}{*}{2} & \multirow{2}{*}{0.041377} & 96.50382 & 0.016575 & 0.691394 & 1.893388 & 0.881480 & 0.013348 \\
\hline & & (5.67277) & (2.28098) & (3.61603) & (3.54248) & $(2.40371)$ & $(0.52508)$ \\
\hline \multirow{2}{*}{3} & \multirow{2}{*}{0.054106} & 88.52570 & 0.175769 & 2.611174 & 7.813090 & 0.860899 & 0.013372 \\
\hline & & (11.0431) & (3.88804) & $(7.51244)$ & $(8.24101)$ & (3.11941) & $(0.69505)$ \\
\hline \multirow{2}{*}{4} & \multirow{2}{*}{0.062523} & 77.44409 & 1.598395 & 6.229480 & 14.07172 & 0.645158 & 0.011159 \\
\hline & & (13.6449) & (4.91899) & (9.93832) & (10.6114) & (3.75551) & $(0.85944)$ \\
\hline \multirow{2}{*}{5} & \multirow{2}{*}{0.068463} & 68.19470 & 3.203541 & 10.47718 & 17.51020 & 0.604388 & 0.009984 \\
\hline & & (15.1006) & (5.88756) & (11.3756) & (11.5442) & (4.45408) & $(0.98312)$ \\
\hline \multirow{2}{*}{6} & \multirow{2}{*}{0.072246} & 62.57373 & 3.815495 & 13.91814 & 19.08180 & 0.601850 & 0.008986 \\
\hline & & (15.8886) & (6.72646) & (12.5425) & (11.8401) & (4.71676) & (1.11640) \\
\hline \multirow{2}{*}{7} & \multirow{2}{*}{0.074381} & 59.58473 & 3.837071 & 16.27591 & 19.71143 & 0.577131 & 0.013722 \\
\hline & & (16.2767) & (7.27787) & (13.4537) & (11.9020) & $(4.87411)$ & (1.16208) \\
\hline \multirow{2}{*}{8} & \multirow{2}{*}{0.075451} & 58.26032 & 3.752897 & 17.61726 & 19.78180 & 0.563850 & 0.023869 \\
\hline & & (16.3434) & (7.90785) & (13.8692) & (11.6682) & (5.02948) & (1.15008) \\
\hline \multirow{2}{*}{9} & \multirow{2}{*}{0.076137} & 57.90487 & 3.685592 & 18.26682 & 19.53468 & 0.578307 & 0.029739 \\
\hline & & (16.4386) & (8.23482) & (13.9643) & (11.2727) & (5.24561) & (1.13374) \\
\hline \multirow{2}{*}{10} & \multirow{2}{*}{0.077134} & 58.22998 & 3.593425 & 18.50098 & 19.04109 & 0.604088 & 0.030431 \\
\hline & & (16.1547) & (8.37956) & (13.9135) & (11.0504) & (5.47450) & (1.13789) \\
\hline
\end{tabular}

$\overline{\text { Cholescky decomposition. }}$

Table 4. VAriance decomposition of LNFDI.

\begin{tabular}{|c|c|c|c|c|c|c|c|}
\hline $\mathrm{P}$ & S.E. & LNGDP & LNCF & LNEM & LNHK & LNOP & LNFDI \\
\hline \multirow{2}{*}{1} & \multirow{2}{*}{0.115830} & 17.29932 & 7.396128 & 7.206174 & 38.85374 & 0.110478 & 29.13416 \\
\hline & & (13.2206) & (8.42181) & (9.69917) & (11.6988) & (1.49086) & (9.68626) \\
\hline \multirow{2}{*}{2} & \multirow{2}{*}{0.162448} & 34.30804 & 6.991520 & 8.593540 & 27.25177 & 1.909847 & 20.94528 \\
\hline & & $(17.2700)$ & (9.01403) & (9.04329) & (11.0561) & (3.98880) & (10.8931) \\
\hline \multirow{2}{*}{3} & \multirow{2}{*}{0.221035} & 20.26019 & 9.409538 & 41.40283 & 14.80446 & 1.450239 & 12.67275 \\
\hline & & (15.1509) & (8.73018) & (15.7645) & (7.51583) & (3.97730) & (7.46979) \\
\hline \multirow{2}{*}{4} & \multirow{2}{*}{0.314697} & 23.46484 & 14.75753 & 46.77095 & 7.601599 & 1.047370 & 6.357711 \\
\hline & & (11.1815) & (9.97991) & (13.0749) & (6.11302) & (3.28182) & (4.07858) \\
\hline \multirow{2}{*}{5} & \multirow{2}{*}{0.434273} & 32.81774 & 15.33247 & 41.57535 & 4.519624 & 2.352853 & 3.401967 \\
\hline & & (13.1413) & (10.0258) & (11.9748) & (5.00215) & (3.75068) & (2.46613) \\
\hline \multirow{2}{*}{6} & \multirow{2}{*}{0.524486} & 36.37425 & 14.84029 & 37.64286 & 5.400585 & 3.401739 & 2.340274 \\
\hline & & (14.7835) & (10.1387) & (11.9053) & (5.95658) & (5.63597) & (1.85783) \\
\hline \multirow{2}{*}{7} & \multirow{2}{*}{0.581562} & 35.83540 & 14.19050 & 36.27988 & 7.731707 & 4.058935 & 1.903586 \\
\hline & & (14.3601) & (10.2897) & (11.9691) & (7.74544) & (7.26185) & (1.62054) \\
\hline \multirow{2}{*}{8} & \multirow{2}{*}{0.617341} & 34.22489 & 14.14679 & 35.87503 & 9.476428 & 4.584425 & 1.692442 \\
\hline & & (14.1988) & (10.5990) & (12.0025) & (9.16433) & (8.40683) & (1.56180) \\
\hline \multirow{2}{*}{9} & \multirow{2}{*}{0.644482} & 32.12340 & 14.78602 & 36.10288 & 10.26365 & 5.169846 & 1.554210 \\
\hline & & (14.1295) & (10.9223) & (12.0125) & (9.71607) & (8.97719) & (1.49571) \\
\hline \multirow{2}{*}{10} & \multirow{2}{*}{0.669527} & 29.89515 & 16.02528 & 36.69007 & 10.12676 & 5.822598 & 1.440148 \\
\hline & & (14.6328) & (11.2131) & (12.2581) & (9.28237) & (9.16418) & (1.42448) \\
\hline
\end{tabular}

Cholescky decomposition. 
Returning to Johansen's test, the VECM representation of the VAR was:

$$
\begin{aligned}
\Delta y_{t}= & Z+\Pi y_{t-1}+\Gamma 1 \Delta y_{t-1}+\Gamma_{2} \Delta y_{t-2} \\
& +\ldots+\Gamma_{k-1} \Delta y_{t-(k-l)}+u_{t} ; \\
S^{-1} B= & Z, S^{-1} A(i)=\Gamma_{i},
\end{aligned}
$$

Here: $\Pi=\Pi_{1}+\Pi_{2}+\ldots+\Pi_{K}-I$; and

$$
\Gamma_{i}=-\left(\Pi_{i+1}+\Pi_{i+2}+\ldots+\Pi_{k}\right) \Pi_{p}
$$

The long-run matrix is:

$$
\Pi=A B^{\prime}: A=n \times r, B^{\prime}=r \times n, \leq n
$$

where: $r$ is the rank of the matrix $\Pi$; $r$ is the reduced rank, that is $r<n$, for co-integration to exist. B' contains the coefficients in the co-integrating relationships between the $\mathrm{n}$ variables; the trace statistic developed by Johansen is used to determine $r$, the number of co-integrating relationships in the VAR.

Relevant economic theory or, economic intuitions regarding the possible linkage between the variables that have been formulated in literature have been employed in the identification of co-integration vectors. To assess the number of co-integrating vectors, type 3 and 4 of deterministic trend specification by Johansen are used. Type 3 excludes the trend from the co-integrating vectors, whilst type 4 does not. Johansen co-integration for both type 3and type 4 reveal four co-integration relations, and $L R$ test is applied to test the existence of trend term, and results (Chi-square $=23.7356$ ) indicate that trend term can be excluded out of the co-integrating estimation. To further identify the co-integrating vectors, constraints on the coefficients in the co-integration vectors and adjustment coefficients is a better choice, so that both the restrictions hold statistically by Chi-square test and in the mean time, all the co-integrating vectors can be identified [15]. According to economic theory and or economic intuitions concerning the possible linkage between the variables, attempts have been made to identify the co-integrating variables.

\subsection{Co-integrating Vectors and VECM}

Endeavors have been made in identifying vectors focusing on the following issues: 1) the long-run relationship between GDP and FDI, and vice versa; 2 ) the major motivation for GDP growth; 3) impact of FDI on domestic capital, i.e., crowd-out effect of FDI on domestic capital; 4) relations between GDP and employment, and other determinants.

Finally, co-integrating vectors have been identified, as shown in Table 5. Restrictions have been given for

Table 5. Identified cointegration vectors.

\begin{tabular}{|c|c|c|c|c|}
\hline \multicolumn{5}{|c|}{ Chi-square(5) 2.067531 Probability 0.946865} \\
\hline Cointegrating Eq: & CointEq1 & CointEq2 & CointEq3 & CointEq4 \\
\hline \multirow[t]{3}{*}{$\overline{L N G D P(-1)}$} & 1.000000 & 1.000000 & 0.774881 & 1.000000 \\
\hline & & & $(0.2286)$ & \\
\hline & & & [3.89846] & \\
\hline $\operatorname{LNCF}(-1)$ & -1.000000 & -1.000000 & 1.000000 & -1.000000 \\
\hline \multirow[t]{3}{*}{$\operatorname{LNEM}(-1)$} & -1.000000 & -7.755302 & 1.000000 & -1.738992 \\
\hline & & $(0.67634)$ & & $(0.4786)$ \\
\hline & & {$[-6.26446]$} & & {$[-6.33673]$} \\
\hline \multirow[t]{3}{*}{$L N O P(-1)$} & -1.000000 & 1.000000 & -7.516979 & -6.095340 \\
\hline & & & $(0.25105)$ & $(0.21047)$ \\
\hline & & & {$[-29.9424]$} & {$[-28.9606]$} \\
\hline \multirow[t]{3}{*}{$L N H K(-1)$} & 0.083012 & -0.371797 & 1.308852 & 1.000000 \\
\hline & $(0.22922)$ & $(0.02628)$ & $(0.13142)$ & \\
\hline & {$[-16.2152]$} & {$[-14.1497]$} & [13.6382] & \\
\hline \multirow[t]{3}{*}{$L N F D I(-1)$} & 0.049843 & 0.414239 & 1.000000 & 1.000000 \\
\hline & $(0.11937)$ & $(0.14632)$ & & \\
\hline & {$[-11.7638]$} & [12.3162] & & \\
\hline$C$ & -21.25214 & 70.15052 & 2.668461 & 25.50702 \\
\hline
\end{tabular}

Cointegration Restrictions:

$\mathrm{B}(1,1)=1, \mathrm{~B}(1,2)=1, \mathrm{~B}(1,3)=1, \mathrm{~B}(1,4)=1, \mathrm{~B}(2,4)=1, \mathrm{~B}(2,1)=1, \mathrm{~B}(2,2)=1, \mathrm{~B}(3,2)=1, \mathrm{~B}(3,6)=1, \mathrm{~B}(3,3)=1, \mathrm{~B}(4,2)=1, \mathrm{~B}(4,5)=1$, $\mathrm{B}(4,6)=1, \mathrm{~B}(4,1)=1, \mathrm{~A}(6,2)=0, \mathrm{~A}(3,4)=0, \mathrm{~A}(6,1)=0, \mathrm{~A}(3,3)=0, \mathrm{~A}(2,1)=0$,

Convergence achieved after 4331 iterations. Restrictions identify all co-integrating vectors LR test for binding restrictions $($ rank $=4)$ : 
individual parameters $\left(\mathrm{B}_{\mathrm{ij}}\right.$ refers to the coefficient on the $j^{\text {th }}$ variable in equation $\mathrm{i}$; and $\mathrm{A}_{\mathrm{ij}}$ denotes the coefficient on the $\mathrm{j}^{\text {th }}$ error correction term in the first difference equation of variable i). Co-integration vectors identified by the restricted co-integration estimation are graphed in Figure 2, and the estimation is shown in Table 5.

All the vectors are I (0) series (Figure 2), though at first glance they might not seem to be so. For vector 1, With both intercept and trend, KPSS LM statistic [16] is 0.092211 (KPSS unit root test [17]), which is not only lower than the $5 \%$ critical value requirement $(0.146000)$, but also lower than $10 \%$ critical value (0.119000); for vector 2 , ADF unit root test statistics, with both trend and intercept, is -4.398120 , far under the value of $5 \%$ critical value(-3.612199); for vector 3 , with trend and intercept, ADF test statistic is -4.511757 , far lower than $5 \%$ critical value (3.644963); for vector4, also with both intercept and trend, ADF statistic is -4.705297 , which well meets with $5 \%$ critical requirement (-3.644963). In summary, all the four vectors are stationary.

Omitting the constant and drift terms, the following relations can be extracted from Table 5:

$$
\begin{aligned}
L N G D P= & 1 * L N C F+1 * L N E M+1 * L N O P \\
& -0.083 * L N H K-0.049 * L N F D I \\
L N K A P=1 * L N G D P+7.755 * L N E M-1 * L N O P & \\
& +0.372 * L N H K-0.414 * L N F D I \\
L N E M=- & 0.775 G D P-1 * L N C F+7.517 L N O P \\
& -1.309 L N H K-1 * L N F D I \\
L N F D I= & -1 * L N G D P-1 * L N C F+1.739 L N E M \\
& +6.095 L N O P
\end{aligned}
$$

1
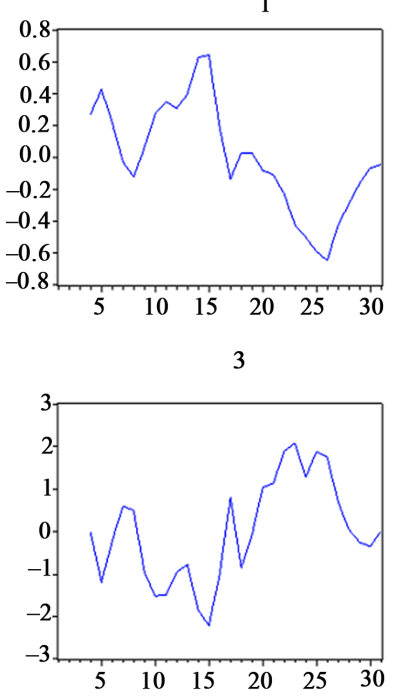

2

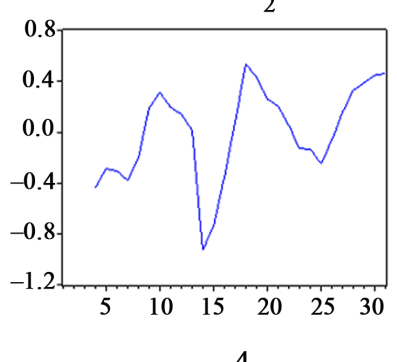

4

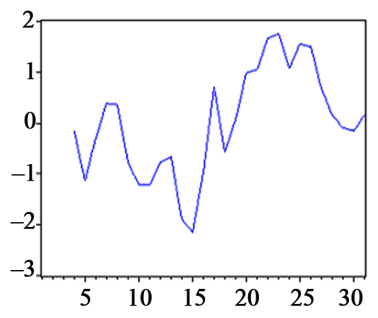

Figure 2. Co-integration vectors.
Findings from (6) show that in the long-run, in the absence of openness, GDP responses positively to the increase of capital formation, openness and employment, whilst negatively to changes of human capital and FDI, with a considerable numerically small number as 0.083 and 0.049 respectively; capital formation, employment and international trade are major driving factors for the increase of output (GDP). Growth in China, as suggested in (6), seems to follow the strategy of domestic capital-intensive development.

Equation (7) provides a feasible explanation for the negative response of long-run output to FDI. The latter tends to reduce domestic capital formation in the longrun and therefore works against the tendency of productive capital formation to enhance long-term economic growth. As a consequence, domestic capital formation might be crowded out by foreign capital and inflow of FDI hence might not be a growth (output) motivator.

Degree of openness, with a co-efficient as 6.095, seems to be a major attractor for FDI inflow, followed by employment (1.739) as suggested by (9), as several studies in the field have suggested. However, FDI reacts negatively to the increase of GDP and promotion of capital formation. With the development of an economy, increasing technology-intensiveness of domestic capital, together with full application of machinery in industry, the superiority ever possessed by foreign capitals over domestic ones seems to tail off, which might lead to lower level of FDI inflow.

The growth of GDP and capital formation indicate that the more of advanced and sophisticated technologies applied, higher ratio of machine to workers in manufacturing process, the more rigid requirements for the labor force; all would squeeze low-end labor force out of job market, therefore decrease employment, as shown in (8); high level of openness provides more opportunities of trading abroad, hence enhance the development of foreign trade oriented domestic enterprises, in the mean time, creating more job opportunities. Furthermore, as indicted by (8), FDI inflow would increase competition and innovation, bring more knowledge-intensive technologies, and speeding up the substitution of machinery to common workers, resulting in the decrease in the number of low-end workers, hence lower level of total employment.

Finally, considerations would be given to the traits of VEC model. The impact of error correction terms on the changes in variables are presented in Table 6, where all variables seem to be endogenous variables, reacting to changes to the equilibrium between them caused by any one of them. However, one variable seems to be a bit of "exogenous", comparing with others, namely, employment, which is somehow statistically insignificant [18]. 
Table 6. VEC model adjustment matrix.

\begin{tabular}{ccccccc}
\hline EC & Dlngdp & Dlncf & Dlnem & Dlnop & Dlnhk & Dlnfdi \\
\hline CoE 1 & -0.082575 & 0.000000 & 0.077817 & 0.351127 & 1.220529 & 0.000000 \\
& $(0.07218)$ & $(0.00000)$ & $(0.04687)$ & $(0.34821)$ & $(0.28332)$ & $(0.00000)$ \\
& {$[-1.14397]$} & {$[\mathrm{NA}]$} & {$[1.66039]$} & {$[1.00837]$} & {$[4.30792]$} & {$[\mathrm{NA}]$} \\
CoE2 & 0.285835 & -1.889943 & -0.105534 & 1.096474 & -4.837503 & 0.000000 \\
& $(0.25534)$ & $(0.38923)$ & $(0.06910)$ & $(1.15383)$ & $(1.31025)$ & $(0.00000)$ \\
& {$[1.11941]$} & {$[-4.85563]$} & {$[-1.52730]$} & {$[0.95029]$} & {$[-3.69204]$} & {$[\mathrm{NA}]$} \\
CoE3 & 0.686713 & -4.366233 & 0.000000 & 4.187658 & -13.19915 & 2.931734 \\
& $(0.65372)$ & $(0.98198)$ & $(0.00000)$ & $(2.88897)$ & $(3.31502)$ & $(0.66913)$ \\
& {$[1.05046]$} & {$[-4.44637]$} & {$[\mathrm{NA}]$} & {$[1.44953]$} & {$[-3.98162]$} & {$[4.38138]$} \\
& -0.821463 & 5.065419 & 0.000000 & -4.711715 & 15.72463 & -3.562006 \\
& $(0.76961)$ & $(1.14399)$ & $(0.00000)$ & $(3.40596)$ & $(3.88671)$ & $(0.77999)$ \\
& {$[-1.06737]$} & {$[4.42786]$} & {$[\mathrm{NA}]$} & {$[-1.38337]$} & {$[4.04574]$} & {$[-4.56673]$} \\
\hline
\end{tabular}

\section{Conclusions}

Efforts have been exerted to the fundamental issues of the role of FDI plays in the process of economic growth of China since the reform and opening up policy, 1978. Conflicting opinions exist in the now rather voluminous theoretical, descriptive and formal econometric studies for China, to which reference has been made in the introduction part of this paper. Endeavors have been focused on the encompassing the various narrow studies in a comprehensive frame work, in which determinants tend to influencing the aggregate output and FDI would be incorporated and to further research the interlinks between each of them. The VAR model is based on the "endogenous theory," which seeks to reduce the adverse impact of diminishing returns and hence generate long-term sustainable growth through capital accumulation.

Findings in this paper can be concluded as follows.

1) In the long-run, relations can be discerned between FDI and GDP. FDI tends to decrease (limitedly) GDP in the long run on the spectacular phenomenon of Chinese literature. FDI inflow tends to be fueled by growth of employment and increasing level of international openness.

2) Growth of GDP seems to be driven by domestic capital formulation and growth of employment, presumably fueled by government infrastructural investment and capital accumulation.

3) FDI tends to have a crowd-out effect on domestic capital via decreasing domestic capital formation, and further reduces aggregate output in the long term, for output response actively to promote capital formation.

4) FDI seems to have a negative impact on growth of employment, whilst the latter increases the former. Therefore, policy prescription shall be target FDI inflow at most technology-sophisticated sectors of the economy, and screen FDI introduced to be complement to but not substitute for domestic capital.

\section{REFERENCES}

[1] H. Zhang Kevin, "Foreign Direct Investment in China," Canadian Foreign Policy, Vol. 13, No. 2, 2006, pp. 35-50. doi:10.1080/11926422.2006.9673427

[2] J. Shan, "A VAR Approach to the Economics of FDI in China,” Applied Economics, Vol. 34, 2002, pp. 885-893. doi:10.1080/00036840110058941

[3] X. Liu, P. Burridge and P. J. N. Sinclair, "Relationships between Economic Growth, Foreign Direct Investment and Trade: Evidence from China," Applied Economics, Vol. 34, 2002, pp. 1433-1440. doi:10.1080/00036840110100835

[4] J. R. Tan, M. Dong and Y. H. Zhou, "The Analyses of FDI and Economic Growth in China," USA-China Business Reviews, Vol. 7, 2004.

[5] D. A. Dickey and W. A. Fuller, "Distribution of the Estimators for Autoregressive Time Series with a Unit Root," Journal of the American Statistical Association, Vol. 74, 1979, pp. 427-431. doi:10.2307/2286348

[6] D. A. Dickey and W. A. Fuller, "Likelihood Ratio Statistics for Autoregressive Time Series with a Unit Root," Econometrica, 1981, Vol. 49, pp. 1057-1072. doi: $10.2307 / 1912517$

[7] P. C. B. Phillips and P. Perron, "Testing for a Unit Root in Time Series Regression,” Biometrika, Vol. 75, 1988, pp. 335-346. doi:10.1093/biomet/75.2.335

[8] C. A. Sims, "Microeconomics and Reality," Econometrica, Modeling Economic Series, Reprinted in: C. W. J. Granger, Ed., Clarendon Press, Oxford, Vol. 48, 1980, pp. 1-48.

[9] R. F. Engle and C. W. J. Granger, "Co-Integration and Error Correction: Representation, Estimation, and Testing," Econometrica, Vol. 55, No. 2, 1987, pp. 251-276. 


\section{doi:10.2307/1913236}

[10] B. S. Bernanke and A. S. Blinder, "The Federal Funds Rate and the Channels of Monetary Transmission," American Economic Review, Vol. 82, No. 4, 1992, pp. 901-921.

[11] J. D. Hamilton, “Time Series Analysis,” Princeton University Press, Princeton, 1994, pp. 355-391.

[12] A. K. Bera and C. M. Jarque, "Effcient Tests for Normality, Homoscedasticity and Serial Independence of Regression Residuals,” Economics Letters, Vol. 3, No. 6, 1980, pp. 255-259.

[13] S. Johansen, "A Stastistical Analysis of Cointegration for I (2) Variables,” Econometric Theory, Vol. 11, No. 1, 1995, pp. 25-59. doi:10.1017/S0266466600009026

[14] K. Juselius and S. Johansen, "Extracting Information from the Data: A Popperian View on Empirical Macro," Discussion Papers, University of Copenhagen, Vol. 5, No.
5, 2005.

[15] A. Banerjee, J. Dolado, J. Galbraith and D. Hendry, "Co-Integration, Error-Correction, and the Econometric Analysis of Non-Stationary Data,” Oxford University Press, 1993. doi:10.1093/0198288107.001.0001

[16] A. Bhargava, "On the Theory of Testing for Unit Roots in Observed Time Series,” Review of Economic Studies, Vol. 53, 1986, pp. 369-384. doi:10.2307/2297634

[17] D. Kwiatkowski, P. C. B. Phillips, P. Schmidt and Y. Shin, "Testing the Null Hypothesis of Stationarity against the Alternative of a Unit Root," Journal of Econometrics, Vol. 54, 1992, pp. 159-178. doi:10.1016/0304-4076(92)90104-Y

[18] R. F. Engle, D. F. Hendry and J. F Richard, "Erogeneity,” Econometrica, Vol. 51, 1983, pp. 277-304. doi:10.2307/1911990 